\title{
Clearance of Atrial Natriuretic Factor by Lung, Liver, and Kidney in Human Subjects and the Dog
}

Alan S. Hollister, Richard J. Rodeheffer, Frederick J. White, John R. Potts, Teruaki Imada, and Tadashi Inagami Departments of Medicine, Biochemistry and Surgery, Vanderbilt University, Nashville, Tennessee 37232

\begin{abstract}
We determined human and canine plasma clearance of atrial natriuretic factor (ANF) by lung, liver, and kidney from arteriovenous differences in plasma ANF and measured organ plasma flow. Human subjects had lower plasma ANF concentrations in the pulmonary vein or the pulmonary capillary wedge position when compared with the pulmonary artery, and both sites yielded pulmonary ANF extraction ratios of $24 \%$. Canine lung ANF extraction was $19 \pm 3 \%$ and pulmonary ANF clearance was $328 \pm 78 \mathrm{ml} / \mathrm{min}$ per $\mathrm{m}^{2}$ vs. $357 \pm 53 \mathrm{ml} / \mathrm{min}$ per $\mathrm{m}^{2}$ in man. Hepatic plasma ANF clearance was $216 \pm 26 \mathrm{ml} /$ min with an extraction ratio of $30 \pm 3 \%$ in humans and $199 \pm 89$ $\mathrm{ml} / \mathrm{min}$ and $36 \pm 6 \%$ in the dog. Renal plasma ANF clearance in human subjects was $78 \pm 12 \mathrm{ml} / \mathrm{min}$ per kidney and correlated well with each kidney's creatinine clearance $(r=0.58, P$ $<0.05)$. The mean renal ANF extraction ratio was $35 \pm 4 \%$ in human subjects and $42 \pm 6 \%$ in the dog.

These data quantitate the specific organ ANF clearances by lung, liver, and kidney in human subjects and in dogs and provide a rationale for elevated plasma ANF levels in cirrhosis, renal failure, and diseases accompanied by reduced perfusion of these organs. These findings support the conclusion that plasma ANF concentrations are dependent upon both the stimuli for ANF secretion as well as the specific organ clearances of ANF.
\end{abstract}

\section{Introduction}

Human plasma atrial natriuretic factor (ANF) ${ }^{1}$ concentrations have been shown to be associated with atrial filling pressures (1-6), atrial size $(1,7)$, and calculated wall tension (7). Thus, volume and/or hormonal stimuli which influence atrial stretch appear to alter human plasma ANF levels. However, several

Parts of these studies were published in abstract form in 1986 (Circulation. 74:II-464) and 1987 (Circulatton. 76:IV-271) 1987. (Clin. Res. 35:334a) and 1988 (Clin. Res. 36:118a).

Address reprint requests to Dr. Hollister, Division of Clinical Pharmacology, Department of Medicine, Vanderbilt University, Nashville, TN 37232. Dr. Rodeheffer's current address is Cardiovascular Disease and Internal Medicine, Mayo Clinic, Rochester, MN 55905. Dr. Potts' current address is Cleveland Clinic Florida, Fort Lauderdale, FL 33309.

Received for publication 31 May 1988 and in revised form 7 September 1988.

1. Abbreviations used in this paper: ANF, human atrial natriuretic factor; PAH, para-aminohippurate.

J. Clin. Invest.

(C) The American Society for Clinical Investigation, Inc.

$0021-9738 / 89 / 02 / 623 / 06 \$ 2.00$

Volume 83, February 1989, 623-628 investigators have found elevated plasma ANF levels in cirrhosis (8-11) and we have found this to be true despite lower atrial pressures and smaller atrial sizes (7). Similarly, plasma ANF concentrations are elevated in renal failure with and without volume overload (12-17), suggesting that reductions in renal and liver function are associated with reduced plasma ANF clearance. Since earlier reports found lower plasma ANF concentrations in the renal and hepatic veins than in the aorta (18, 19), these organs appear to clear endogenous ANF from plasma. Unfortunately, renal and hepatic blood flows were not determined in these studies so it was not possible to estimate specific organ clearances of ANF. However, these observations suggest that plasma ANF levels are determined by variations in ANF clearance in addition to alterations in stimuli for ANF release.

We have found that plasma ANF concentrations are consistently lower in the pulmonary capillary wedge position than in the pulmonary artery (1). This finding suggests that the pulmonary vascular bed is also a site for removal of ANF from the circulation. To better understand the factors influencing plasma ANF concentrations, we undertook experiments to determine the specific clearances of ANF by lung, hepatic/ splanchnic, and renal vascular beds in human subjects and in the dog. Our findings indicate that each of these vascular beds clears large amounts of plasma ANF and thereby influences the endogenous plasma ANF concentration.

\section{Methods}

All procedures in this study were approved by the Vanderbilt University Committee for the Protection of Human Subjects or the Vanderbilt University Animal Care and Use Committee.

Human studies. For the pulmonary and hepatic clearance studies, all subjects were undergoing cardiac catheterization for clinical indications. Two groups were studied for pulmonary clearance of ANF; 39 patients ( 20 male, 19 female) with coronary artery disease, cardiomyopathy, valvular disease or pulmonary hypertension, ages 18-74 (mean \pm SD, 53 \pm 15 ) yr, with New York Heart Association classification ranging from I to IV (mean 1.9); and 5 patients ( 1 male, 4 female), ages 19-55 with congenital heart disease, three with atrial septal defects, one with pulmonary stenosis and a patent foramen ovale, and one with an anomalous pulmonary vein, in whom direct collection of pulmonary venous blood was possible. Cardiac output/pulmonary blood flow was determined with thermodilution and/or indocyanine green dye techniques.

18 subjects ( 10 male, 8 female, ages $30-67$, mean $52 \pm 12$ yr) studied for hepatic clearance of ANF received a $10-\mathrm{mg}$ bolus followed by a $1.2 \mathrm{-mg} / \mathrm{min}$ infusion of indocyanine green for $20 \mathrm{~min}$ before triplicate sampling of aortic and hepatic vein blood for ANF and steady-state indocyanine green determinations (20). Hepatic plasma flow and ANF clearance were calculated by the Fick principle. All 18 subjects had normal liver function tests, normal serum creatinine, and no clinical evidence of hepatic dysfunction.

Eight subjects (six male, two female) studied for renal ANF clearance (ages $47-68$, mean $57 \pm 7$ yr) were hypertensive subjects undergo- 
ing renal vein renin sampling and split renal function studies for hypertensive evaluation. Serum creatinine was normal in all subjects. ANF blood samples were drawn from the renal veins and the femoral artery for determination of renal ANF extraction. On a separate day, steady-state infusions of para-aminohippurate (PAH) were established and ureters were separately cannulated for urine collections in order to determine renal plasma flow and creatinine clearance in triplicate (21).

Animal studies. Nine male mongrel dogs (weight: $20.9 \pm 2.7 \mathrm{~kg}$ ) underwent thoracotomy and laparotomy for placement of indwelling catheters in the pulmonary, hepatic, and renal veins, and the pulmonary and aortic arteries. The lines were tunnelled subcutaneously to an exit between the scapulae and patency was maintained by heparinized saline flushes. The animals were allowed to recover and were studied 3-7 d later under either sedation or pentobarbital anesthesia. When an animal was studied more than once, 3-8 d elapsed between experiments. Catheter placement was confirmed at the time of study by fluoroscopy or autopsy. Hepatic and renal plasma flows were determined at the time of ANF sampling by steady-state indocyanine green and PAH infusions, respectively. Pulmonary blood flow was measured by the thermodilution technique.

Analyses. Plasma immunoreactive ANF was determined as previously described $(1,6)$ after $\mathrm{C}-18$ Sep-Pak extraction, lyophilization, and reconstitution in radioimmunoassay buffer. Intraassay and interassay coefficients of variation were 7 and $10 \%$, respectively, and the limit of assay sensitivity was $4 \mathrm{pg} / \mathrm{ml}$. Some of the subjects in the first experiment were studied at a time when the limits of sensitivity were 18 and $12 \mathrm{pg} / \mathrm{ml}$. HPLC separation of ANF in selected subjects indicated that $<5 \%$ of the assayable ANF was present in either a 21 or 24 amino acid form of ANF or as the $\beta$-ANF dimer (22).

Plasma indocyanine green dye concentrations were determined by spectrophotometry within $4 \mathrm{~h}$ of sampling, using each subject's plasma in the standard curve. Plasma PAH was measured by diazo derivatization followed by spectrophotometry, as previously described (23).

Statistics. Within subjects data were analyzed by the paired $t$ test, analysis of variance, and linear regression. Probabilities $<0.05$ were considered significant. In those instances where grouped data were not normally distributed, logarithmic transformations yielded normally distributed data that revealed differences equal to or greater than those reported for ordinal data. Means derived from the logarithmic transformations are shown in the figures and figure legends, while untransformed data are expressed in the text. The arterial-venous differences for each organ system studied were normally distributed, so calculations of extraction rate, extraction ratio, and clearance were performed on untransformed data.

\section{Results}

Pulmonary clearance of $A N F .39$ patients underwent blood sampling from the pulmonary artery, pulmonary capillary wedge position, and the aorta. The pulmonary capillary wedge catheter position was verified by fluoroscopy and oxygen saturation measurements. Plasma ANF levels fell from a mean of $188 \pm 40 \mathrm{pg} / \mathrm{ml}$ (mean \pm SEM) in the pulmonary artery to $131 \pm 29$ in the pulmonary capillary wedge position, a change of $57 \pm 14 \mathrm{pg} / \mathrm{ml}(P<0.0005)$ (Fig. 1). Each of the 39 subjects whose pulmonary artery ANF concentrations were above the assay limit of detection demonstrated a fall in ANF between the pulmonary artery and wedge position. As a group, this resulted in a mean extraction ratio of $24 \pm 3 \%$ and a removal of $137 \pm 33 \mathrm{ng}$ ANF per minute from the circulation. Mean ANF clearance by the pulmonary capillary bed was $634 \pm 82 \mathrm{ml} /$ min. All but one of the subjects showed an increase or no change in plasma ANF when aortic levels (mean 195 \pm 43 $\mathrm{pg} / \mathrm{ml}, P<0.0005$ ) were compared with the pulmonary capillary wedge position, demonstrating an increase in plasma ANF concentrations during transit of the left side of the heart.

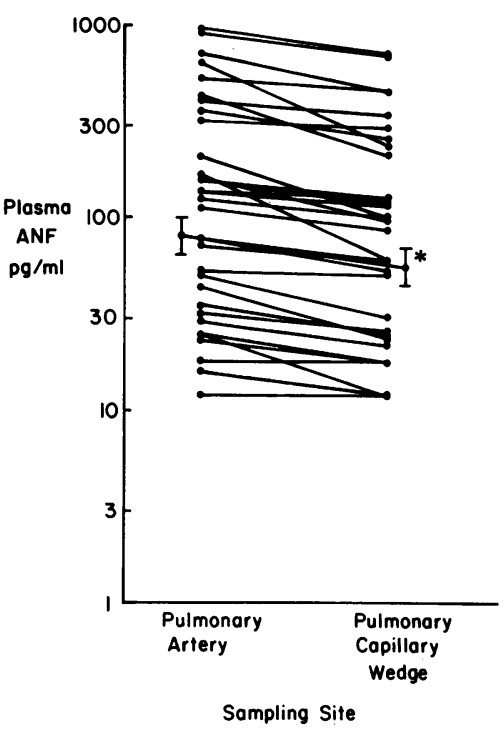

Figure 1. Pulmonary artery and pulmonary capillary wedge position plasma ANF concentrations in 39 human subjects. The pair of points from each subject are connected by the lines. The vertical axis is logarithmic to normalize the distribution of ANF values in each group. The points with standard error bars represent the means of each group after logarithmic transformation (PA: $80 \pm$ antilog 0.095 $\mathrm{pg} / \mathrm{ml}$; PCW: $57 \pm$ anti$\log 0.092 \mathrm{pg} / \mathrm{ml} ;{ }^{*} P$ $<0.0005$ by paired $t$ test).

Because of the possibility that blood obtained from the pulmonary capillary wedge position does not have the same ANF concentration as pulmonary venous blood, we obtained triplicate or quadruplicate paired, simultaneous blood samples from the pulmonary artery and pulmonary vein in five subjects in whom direct access to the pulmonary vein was possible. Each of the 16 paired samples exhibited a reduction in plasma ANF concentration across the pulmonary vascular bed, from $141 \pm 24 \mathrm{pg} / \mathrm{ml}$ in the pulmonary artery to $107 \pm 19$ in the pulmonary vein (difference $=34 \pm 12 \mathrm{pg} / \mathrm{ml}, P<0.001$ ) (Fig. 2). The calculated extraction ratio was $24 \pm 5 \%$, virtually identical to that obtained with sampling at the pulmonary capillary wedge position. Despite somewhat lower plasma ANF concentrations than the foregoing series, clearance of ANF was greater $(840 \pm 178 \mathrm{ml} / \mathrm{min})$ owing to a greater pulmonary plasma flow in the latter group $(2.9 \pm 0.2$ vs. $3.6 \pm 0.7$ liters/min).

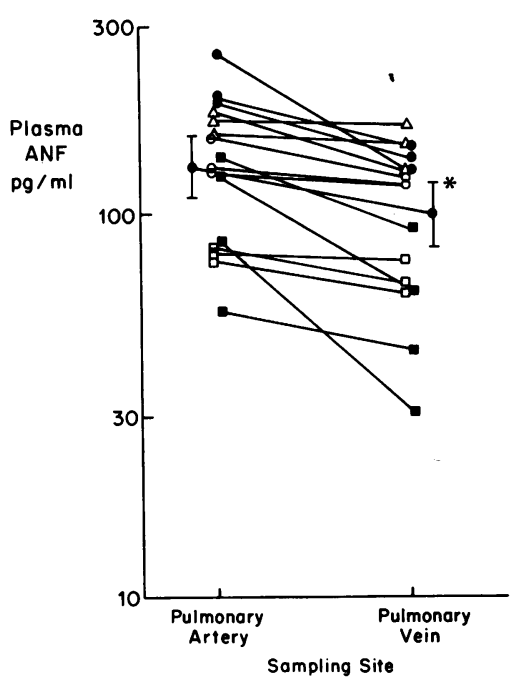

Figure 2. Pulmonary artery and pulmonary vein concentrations of plasma ANF in five human subjects. Each of 16 simultaneous, paired samples is connected by the lines. The individual patients are indicated by different symbols and the symbols with error bars represent the group mean. The vertical axis is logarithmic and the means \pm standard errors plotted (PA: 132 tanti$\log 0.078 \mathrm{pg} / \mathrm{ml}$; PV:

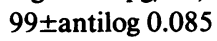
$\mathrm{pg} / \mathrm{ml} ;{ }^{*} P<0.001$ by ANOVA) were determined after logarithmic transformation. 


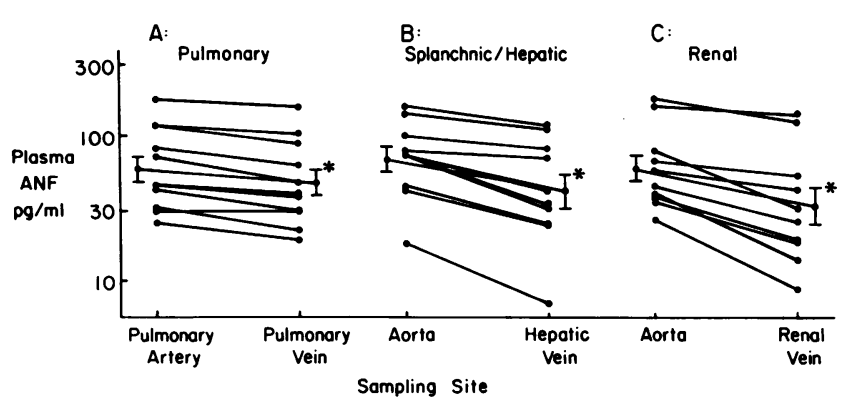

Figure 3. (A) Pulmonary artery and pulmonary vein plasma ANF concentrations in 11 experiments on 6 dogs. $(B)$ Aortic and hepatic vein plasma ANF concentrations in 10 experiments on 8 dogs. $(C)$ Aortic and renal vein plasma ANF concentrations in 10 experiments on 7 dogs. Each point is the mean of duplicate or triplicate determinations and the lines connect simultaneous arterial and venous samples. The vertical axis is logarithmic and the points with standard error bars were calculated after logarithmic transformation of the data. ${ }^{*} P<0.0005$ by paired $t$ test.

In 11 experiments on 6 dogs, triplicate paired blood samples were obtained simultaneously from the pulmonary artery and vein for analysis of ANF. Pulmonary artery plasma ANF concentration $(72 \pm 14 \mathrm{pg} / \mathrm{ml})$ fell across the pulmonary capillary bed $(59 \pm 13 \mathrm{pg} / \mathrm{ml})$, yielding a mean intraindividual difference of $12 \pm 2 \mathrm{pg} / \mathrm{ml}(P<0.0005)$ and an extraction ratio of $19 \pm 3 \%$ (Fig. $3 \mathrm{~A}$ ). The removal rate of ANF was $17 \pm 3 \mathrm{ng} / \mathrm{min}$ and pulmonary plasma clearance of ANF was $269 \pm 65 \mathrm{ml} /$ min. When expressed in terms of cardiac index, the pulmonary plasma clearance of ANF in dogs $(328 \pm 78 \mathrm{ml} / \mathrm{min}$ per $\mathrm{m}^{2}$ ) was quite similar to that found in the first group of human subjects $\left(357 \pm 53 \mathrm{ml} / \mathrm{min}\right.$ per $\mathrm{m}^{2}$ ). (See Table I for comparisons of human and canine plasma extractions and clearances of ANF.)

Hepatic/splanchnic clearance of $A N F .18$ subjects undergoing cardiac catheterization for clinical indications received a $10-\mathrm{mg}$ bolus followed by a $1.2-\mathrm{mg} / \mathrm{min}$ indocyanine green infusion for $20 \mathrm{~min}$ before blood sampling. Triplicate, simultaneous paired blood samples for ANF and indocyanine green were obtained from the hepatic vein and abdominal aorta in each subject. Mean aortic plasma ANF concentration was $338 \pm 47 \mathrm{pg} / \mathrm{ml}$ and fell to $242 \pm 38$ in the hepatic vein (Fig. 4). Each pair of 54 simultaneous samples demonstrated a fall in

Table I. ANF Organ Clearances

\begin{tabular}{|c|c|c|c|c|c|c|}
\hline \multirow[b]{2}{*}{ Organ } & \multicolumn{3}{|c|}{ Human } & \multicolumn{3}{|c|}{ Canine } \\
\hline & $n$ & $\begin{array}{l}\text { Extraction } \\
\text { ratio \% }\end{array}$ & Clearance & $n^{8}$ & $\begin{array}{l}\text { Extraction } \\
\text { ratio } \%\end{array}$ & Clearance \\
\hline & & & $\mathrm{ml} / \mathrm{min}$ & & & $\mathrm{ml} / \mathrm{min}$ \\
\hline \multirow[t]{2}{*}{ Lung } & 39 & $24 \pm 3$ & $634 \pm 82$ & 11 & $19 \pm 3$ & $269 \pm 65$ \\
\hline & $16^{*}$ & $24 \pm 5$ & $840 \pm 178$ & & & \\
\hline Liver/splanchnic & $18^{\ddagger}$ & $30 \pm 3$ & $216 \pm 26$ & 10 & $36 \pm 6$ & $199 \pm 89$ \\
\hline Kidney & 12 & $35 \pm 4$ & $78 \pm 12$ & 10 & $42 \pm 6$ & $79 \pm 15$ \\
\hline
\end{tabular}

* 16 paired arterial and venous determinations on five subjects.

₹ 54 paired determinations on 18 subjects.

${ }^{\S}$ All canine studies represent triplicate ANF determinations on simultaneous, paired arterial and venous samples.

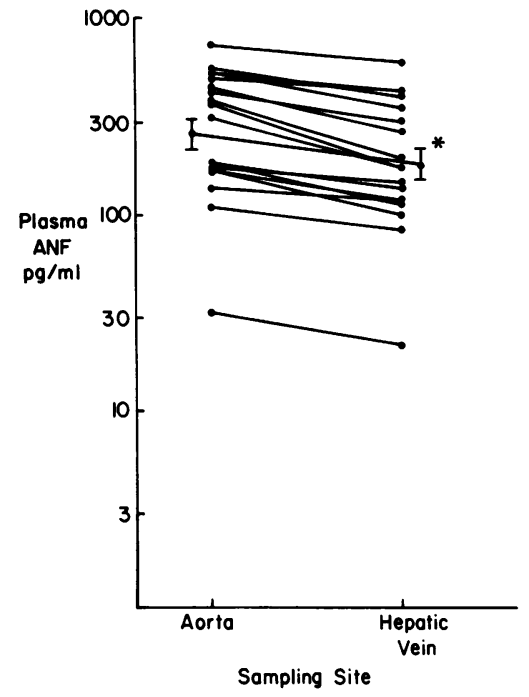

Figure 4. Aortic and hepatic vein plasma concentrations in 18 human subjects. Each point is the mean of triplicate samples and the lines connect the values obtained in each patient. The vertical axis is logarithmic and the means \pm standard errors plotted (Ao: $262 \pm$ antilog 0.079 $\mathrm{pg} / \mathrm{ml}$; HV: $186 \pm$ anti$\log 0.080 \mathrm{pg} / \mathrm{ml} ;{ }^{*} P$ $<0.0005$ by paired $t$ test) were determined after logarithmic transformation.

plasma ANF concentration across the hepatic/splanchnic circulation for a mean intraindividual difference of $97 \pm 14 \mathrm{pg} / \mathrm{ml}$ $(P<0.0005)$, extraction ratio of $30 \pm 3 \%$ and a plasma clearance of $216 \pm 26 \mathrm{ml} / \mathrm{min}$ (Table I). Mean hepatic blood flow was $1,195 \pm 67 \mathrm{ml} / \mathrm{min}$.

In 10 experiments on 8 dogs with chronically implanted hepatic vein and aortic cannulae, aortic plasma ANF levels fell from $82 \pm 14 \mathrm{pg} / \mathrm{ml}$ to $55 \pm 12$ in the hepatic vein, yielding a $27 \pm 4 \mathrm{pg} / \mathrm{ml}(P<0.0005)$ difference across the vascular bed (Fig. $3 B$ ). Extraction ratio for ANF was $36 \pm 6 \%$ and clearance was $199 \pm 89 \mathrm{ml} / \mathrm{min}$ (Table I).

To determine the relative contribution of the splanchnic versus the hepatic circulations to the removal of ANF from plasma, an additional four animals had portal vein catheters chronically implanted. Aortic, portal vein, and hepatic vein ANF concentrations were $54 \pm 4,31 \pm 8$, and $27 \pm 8 \mathrm{pg} / \mathrm{ml}$, respectively. This yielded an extraction ratio for the splanchnic circulation of $43 \pm 3 \%$ and for the hepatic circulation of $16 \pm 6 \%$.

Renal clearance of $A N F$. Eight hypertensive patients undergoing blood sampling for renal vein renin had renal vein and femoral artery blood samples obtained for plasma ANF determinations. On a separate day, these subjects underwent split renal function studies for determination of renal plasma flow and creatinine clearance of each kidney. Of 12 evaluable kidneys, femoral artery plasma ANF concentrations were $124 \pm 15 \mathrm{pg} / \mathrm{ml}$ and renal vein ANF levels were $82 \pm 10 \mathrm{pg} / \mathrm{ml}$, yielding an intraindividual difference of $42 \pm 8 \mathrm{pg} / \mathrm{ml}(P$ $<0.0005$ ) across the renal vascular bed (Fig. 5). The extraction ratio averaged $35 \pm 4 \%$ and plasma $A N F$ clearance was $78 \pm 12$ $\mathrm{ml} / \mathrm{min}$ per kidney (Table I) compared to a mean creatinine clearance of $69 \pm 7 \mathrm{ml} / \mathrm{min}$ per kidney. The mean ratio of renal ANF clearance to creatinine clearance in each kidney was $1.1 \pm 0.1$, and the two clearances correlated significantly $(r$ $=0.58, P<0.05)$.

In 10 experiments performed in triplicate on 7 dogs with chronically implanted aortic and renal vein catheters, plasma ANF fell from $74 \pm 17 \mathrm{pg} / \mathrm{ml}$ in the aorta to $49 \pm 15 \mathrm{pg} / \mathrm{ml}$ in the renal vein (Fig. $3 C$ ). This yielded a significant intraindividual ANF difference of $25 \pm 5 \mathrm{pg} / \mathrm{ml}(P<0.0005)$ across the kidney and a mean extraction ratio of $42 \pm 6 \%$. Simultaneous infusion 


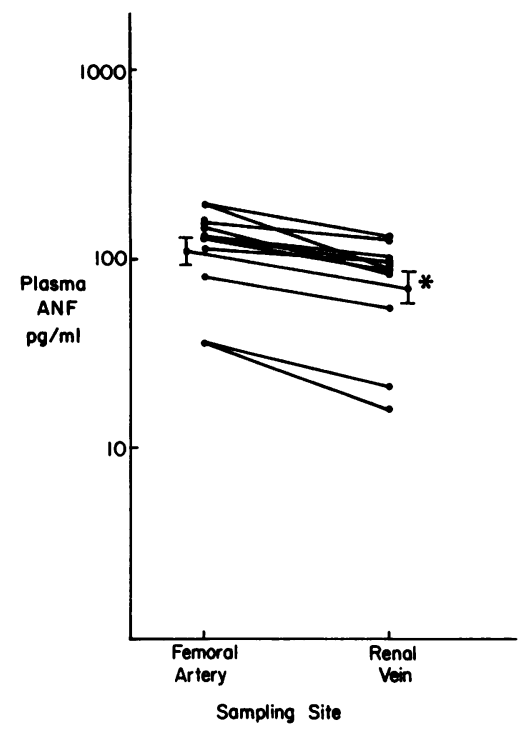

Figure 5. Femoral artery and renal vein plasma ANF concentrations from 12 kidneys in 8 human subjects. The lines connect the values for each subject. The vertical axis is logarithmic and the means \pm standard errors of the groups (FA: $110 \pm$ antilog 0.072 $\mathrm{pg} / \mathrm{ml}$; RV: $71 \pm$ antilog $0.084 \mathrm{pg} / \mathrm{ml} ;{ }^{*} P$ $<0.0005$ by paired $t$ test) were calculated after logarithmic transformation.

of PAH under steady-state conditions with duplicate aortic and renal vein sampling determined the individual renal plasma flow as $188 \pm 35 \mathrm{ml} / \mathrm{min}$, and a plasma ANF clearance of $79 \pm 15 \mathrm{ml} / \mathrm{min}$ per kidney (Table I).

Other vascular beds. In 11 human subjects from the first experimental group, blood sampled from the superior vena cava showed plasma ANF concentrations of $172 \pm 35 \mathrm{pg} / \mathrm{ml}$ compared to aortic plasma ANF levels of $220 \pm 56 \mathrm{pg} / \mathrm{ml}$. The mean difference of $48 \pm 30 \mathrm{pg} / \mathrm{ml}(P<0.1)$ yielded a net extraction ratio of $8.9 \pm 10.2 \%$ for the vascular beds draining into the superior vena cava.

13 plasma ANF samples obtained from the low inferior vena cava during the renal clearance studies showed ANF concentrations of $73 \pm 10 \mathrm{pg} / \mathrm{ml}$ compared to $118 \pm 13 \mathrm{pg} / \mathrm{ml}$ in the femoral artery. This yielded a significant $45 \pm 9 \mathrm{pg} / \mathrm{ml}(P$ $<0.0005$ ) difference between these sites, and a mean extraction ratio of $38 \pm 5 \%$ for the femoral vascular bed.

\section{Discussion}

These data demonstrate that the pulmonary, splanchnic/hepatic and renal circulations are important sites of endogenous plasma ANF clearance in human subjects and in the dog. Our human pulmonary extraction ratios showed excellent agreement between studies employing pulmonary capillary wedge position and pulmonary vein sampling sites, and good agreement between the human and dog studies despite considerably higher plasma ANF levels in the humans. The extraction ratios were also comparable to the 26 and $14 \%$ reduction in ANFlike bioactivity found after passage through isolated guinea pig lungs (24). Thus, our in vivo studies and in vitro studies of other workers demonstrated extraction of plasma ANF during transit of the pulmonary circulation. When compared with the other organs studied, the pulmonary vascular bed accounts for the largest mass of plasma ANF removed and the greatest clearance measured.

The mechanisms by which plasma ANF may be removed during pulmonary transit are not known. Although incubation with whole blood or buffy coat fractions of blood results in a loss of ANF-like bioactivity (25), the rate is quite slow (34-51\% loss per hour) and unlikely to be of consequence in a vascular bed with a transit time of a few seconds. Alternative mecha- nisms for ANF removal include receptor binding followed by removal, diffusion into lymphatics and/or tissue uptake and degradation. In vitro studies with homogenates of lung have demonstrated a rapid loss of radiolabeled ANF during incubation (26), indicating the presence of proteases in lung capable of degrading ANF. Although the capacity of receptors for ANF to remove large quantities from the plasma is limited, physiological (27-29) and receptor binding studies (30) suggest their presence in the pulmonary circulation.

It is interesting to note that aortic plasma ANF concentrations in the human experiments were consistently higher than the corresponding pulmonary capillary wedge position concentrations and virtually equal to the pulmonary artery concentrations. This implies secretion of ANF into the blood by the left side of the heart. This may also explain why other investigators reported no extraction of ANF by the pulmonary circulation when they sampled blood from the aorta (31) or the femoral artery (19). Since our previous work has shown high left atrial and low left ventricular tissue levels of ANF (1), these findings suggest that ANF may be released directly into blood at the level of the left atrium, probably via the Thebesian veins.

The splanchnic and hepatic vascular beds receive $\sim 25 \%$ of the cardiac output. Our human studies indicate that plasma ANF is consistently reduced on transit of this vascular bed, yielding an extraction ratio of 30\%, mass removal of $68 \mathrm{ng}$ $\mathrm{ANF} / \mathrm{min}$, and a plasma ANF clearance of $216 \mathrm{ml} / \mathrm{min}$. These data extend the extraction ratios reported by others $(10,18,19)$ by simultaneous determinations of hepatic plasma flow, enabling the calculation of ANF clearance. The dog studies support the clearance of ANF by the splanchnic circulation and suggest that a large portion of ANF removal may be occurring in the organs draining into the portal vein. However, approximately one-third of hepatic blood flow enters the liver directly by way of the hepatic artery, so it is not possible with our portal blood sampling experiments to attribute the majority of ANF removal to nonhepatic splanchnic sites. Although the mechanism and rate of ANF removal is not identified by these studies, our preliminary studies with ${ }^{125}$ I-ANF perfusion of rat liver in vitro indicate a 100 -fold concentration of radioactivity in the bile. Finally, this elucidation of the role of the splanchnic circulation in plasma ANF clearance may explain the elevations in plasma ANF concentration reported by us and others in patients with cirrhosis $(7-11,22)$.

The data for pulmonary and hepatic ANF clearance in patients with varying degrees of cardiac impairment suggest ANF clearance may be reduced by decreased cardiac function. There were weak negative correlations between cardiac output and pulmonary ANF clearance $(r=-0.138, P=\mathrm{NS})$, pulmonary ANF extraction ratio $(r=-0.389, P<0.05)$, and hepatic ANF extraction ratio $(r=-0.116, P=\mathrm{NS})$, but not hepatic clearance $(r=0.112, P=\mathrm{NS})$. Interestingly, New York Heart Association Class showed a higher degree of association with hepatic ANF clearance and extraction $(r=-0.417, P<0.1$, and $r=-0.386, P>0.1)$ than with the same pulmonary parameters $(r=0.054, P=\mathrm{NS}$, and $r=0.180, P=\mathrm{NS}$, respectively). The negative correlations suggest that cardiac impairment may be associated with reduced ANF clearance by these organs and may contribute to raised ANF levels in heart failure.

Previous reports have found lower renal vein plasma ANF concentrations than are present in the arterial system $(18,19)$, 
but renal blood flow, and hence renal clearance of ANF was not determined. Our human studies on eight patients averaged a 35\% extraction fraction and, using renal plasma flow determined on a separate day, a renal clearance of $78 \pm 12 \mathrm{ml} / \mathrm{min}$ per kidney. There was a good correlation between the creatinine clearance of the kidney and its ANF clearance, in agreement with our earlier report of reduced ANF clearance in kidneys with renal artery stenosis (32). Our dog studies utilized simultaneous determinations of renal plasma flow and ANF removal by the kidneys. The $42 \%$ extraction of ANF and 79 $\mathrm{ml} / \mathrm{min}$ per kidney ANF clearance are in good agreement with the human data. The somewhat lower extraction ratios in the human data may reflect the fact that all of the human subjects were hypertensive.

The mechanisms for ANF clearance by the kidney were not directly determined in this study. The ANF molecule is sufficiently small for filtration to occur and renal tubule brush border proteases have been reported to rapidly degrade ANF $(33,34)$. In addition, receptors for ANF appear to be present in the renal vasculature and glomeruli (30) which may contribute in a small way to the removal of plasma ANF. Since the renal clearance of ANF exceeds the creatinine clearance, a postglomerular component of renal ANF clearance also may be present. On administration of pharmacological doses of ANF, renal plasma flow is redistributed and filtration rate increases $(27,29)$, suggesting that large concentrations of ANF may hasten its own clearance. Thus, plasma ANF clearance determinations based on pharmacologically active ANF doses may yield higher ANF clearance values and shorter half-lives than are present at physiological levels. The high degree of ANF clearance by kidneys may explain, in part, the elevated ANF levels found in chronic renal failure and dialysis dependent patients, even when cardiac filling pressures and intravascular volume are reduced $(12,13,15-17)$.

Clearly, other tissues and/or blood remove immunoreactive ANF from plasma. With a limited number of samples, we found that superior vena cava plasma ANF concentrations averaged $91 \%$ of aortic levels, implying some disappearance of ANF during transit of the vascular beds of the upper body. Similarly, blood samples from the low inferior vena cava had lower ANF concentrations than femoral artery samples, and the mean extraction ratio across this peripheral vascular bed was $38 \%$. Thus, peripheral vascular beds remove ANF from the circulation and may contribute to its total body clearance. In the absence of blood flow determinations through these vascular beds, however, specific clearance cannot be estimated.

In summary, we have measured specific organ clearances of plasma ANF in the pulmonary, splanchnic/hepatic, and renal vascular beds in human subjects and dogs. The high degree of ANF clearance by the lung is largely compensated for by release of ANF into the blood during passage through the left side of the heart. The renal and splanchnic/hepatic vascular beds also contribute significantly to ANF clearance, and these findings may explain the elevations in plasma ANF found in renal failure and cirrhosis. Taken together, these findings indicate that the control of plasma ANF concentrations is dependent not only on the stimuli associated with ANF release, but also on the efficacy of ANF clearance by organs and peripheral tissues.

\section{Acknowledgments}

The authors express their appreciation to Virginia Haile, R.N., Cheryl K. Stewart, R.N., the Vanderbilt Cardiac Catheterization Laboratory and Radiology personnel for their assistance in data collection, to Drs. Grant Wilkinson and John A. Oates for manuscript review, to physicians and housestaff of Vanderbilt University for identification and referral of appropriate subjects, and to Dorothea Boemer for manuscript preparation.

\section{References}

1. Rodeheffer, R. J., I. Tanaka, T. Imada, A. S. Hollister, D. Robertson, and T. Inagami. 1986. Atrial pressure and secretion of atrial natriuretic factor into the human central circulation. J. Am. Coll. Cardiol. 8:18-26.

2. Sato, F., K. Kamoi, Y. Wakiya, T. Ozawa, O. Arai, M. Ishibashi, and T. Yamaji. 1986. Relationship between plasma atrial natriuretic peptide levels and atrial pressure in man. J. Clin. Endocrinol. Metab. 63:823-827.

3. Burnett, Jr., J. C., P. C. Kao, D. C. Hu, D. W. Heser, D. Heublein, J. P. Granger, T. J. Opgenorth, and G. S. Reeder. 1986. Atrial natriuretic peptide elevation in congestive heart failure in the human. Science (Wash. DC). 231:1145-1147.

4. Richards, A. M., J. G. F. Cleland, G. Tonolo, G. D. McIntyre, B. J. Leckie, H. J. Dargie, S. G. Ball, and J. I. S. Robertson. 1986. Plasma $\alpha$ natriuretic peptide in cardiac impairment. Br. Med. J. 293:409-412.

5. Raine, A. E. G., P. Erne, E. Burgisser, F. B. Muller, P. Bolli, F. Burkart, and F. R. Buhler. 1986. Atrial natriuretic peptide and atrial pressure in patients with congestive heart failure. N. Engl. J. Med. 315:533-537.

6. Hollister, A. S., I. Tanaka, T. Imada, J. Onrot, I. Biaggioni, D. Robertson, and T. Inagami. 1986. Sodium loading and posture modulate human atrial natriuretic factor plasma levels. Hypertension. 8:II-106-II-111.

7. Hollister, A. S., B. F. Byrd III, J. R. Potts, C. K. Parrish, T. Imada, and T. Inagami. 1986. Plasma atrial natriuretic factor levels correlate with right atrial pressure, echocardiographic dimensions and calculated wall tension in human subjects. Circulation. 74:II-21. (Abstr.)

8. Gerbes, A. L., R. M. Arendt, D. Ritter, D. Jungst, J. Zahringer, and G. Paumgartner. 1985. Plasma atrial natriuretic factor in patients with cirrhosis. N. Engl. J. Med. 313:1609-1610.

9. Morgan, T., T. Imada, and T. Inagami. 1986. Atrial natriuretic protein (ANP) in the hepatorenal syndrome. Hepatology. 6:1215. (Abstr.)

10. Kawasaki, H., J. Uemasu, N. Maeda, C. Hirayama, T. Kobayashi, and H. Sakurai. 1987. Plasma levels of atrial natriuretic peptide in patients with chronic liver disease. Am. J. Gastroenterol. 82:727-731.

11. Gerbes, A. L., R. M. Arendt, and G. Paumgartner. 1987. Atrial natriuretic factor. Possible implications in liver disease. J. Hepatol. 5:123-132.

12. Hollister, A. S., C. M. Arzubiaga, T. Imada, W. J. Stone, D. Robertson, and T. Inagami. 1986. Elevated plasma atrial natriuretic factor levels in renal failure patients: No change during hemodialysis. Clin. Res. 34:598a. (Abstr.)

13. Hollister, A. S., W. J. Stone, T. Imada, and T. Inagami. 1988. Atrial natriuretic factor reduction during dialysis is due to volume loss and not to dialysance. Clin. Res. 36:364a. (Abstr.)

14. Rascher, W., T. Tulassay, and R. E. Zang. 1985. Atrial natriuretic peptide in plasma of volume-overloaded children with chronic renal failure. Lancet. ii:303-305.

15. Hasegawa, K., Y. Matsushita, T. Inoue, H. Morii, M. Ishibashi, and T. Yamaji. 1986. Plasma levels of atrial natriuretic peptide in 
patients with chronic renal failure. J. Clin. Endocrinol. Metab. 63:819-822.

16. Anderson, J. V., A. E. G. Raine, A. Proudler, and S. R. Bloom. 1986. Effect of haemodialysis on plasma concentrations of atrial natriuretic peptide in adult patients with chronic renal failure. J. Endocrinol. 110:193-196.

17. Shenker, Y., F. K. Port, R. D. Swartz, M. D. Gross, and R. J. Grekin. 1987. Atrial natriuretic hormone secretion in patients with renal failure. Life Sci. 41:1635-1644.

18. Crozier, I. G., M. G. Nicholls, H. Ikram, E. A. Espiner, T. G. Yangle, and S. Jans. 1986. Atrial natriuretic peptide in humans. Production and clearance by various tissues. Hypertension. 8:II-11-II-15.

19. Schutten, H. J., J. H. Henriksen, and J. Warberg. 1987. Organ extraction of atrial natriuretic peptide (ANP) in man. Significance of sampling site. Clin. Physiol. 7:125-132.

20. Leevy, C. M., C. L. Mendenhall, W. Lesko, and M. M. Howard. 1962. Estimation of hepatic blood flow with indocyanine green. $J$. Clin. Invest. 41:1169-1179.

21. Stamey, T. A., I. J. Nudelman, P. H. Good, F. N. Schwentker, and F. Hendricks. 1961. Functional characteristics of renovascular hypertension. Medicine (Baltimore). 40:347-394.

22. Morgan, T. R., T. Imada, A. S. Hollister, and T. Inagami. 1988. Plasma human atrial natriuretic factor in cirrhosis and ascites with and without functional renal failure. Gastroenterology. 95:1641-1647.

23. Varley, H. 1967. Practical Clinical Biochemistry. Interscience Books, Inc., New York. 181-182.

24. Weselcouch, E. O., W. R. Humphrey, and J. W. Aiken. 1985. Effect of pulmonary and renal circulations on activity of atrial natriuretic factor. Am. J. Physiol. 249:R595-R602.

25. Veress, A. T., C. K. Chong, and H. Sonnenberg. 1985. Inactivation of atrial natriuretic factor in blood. Can. J. Physiol. Pharmacol. 63:1615-1617.

26. Tang, J., R. J. Webber, D. Chang, J. K. Chang, J. Kiang, and
E. T. Wei. 1984. Depressor and natriuretic activities of several atrial peptides. Regul. Peptides. 9:53-59.

27. Cody, R. J., S. A. Atlas, J. H. Laragh, S. H. Kubo, A. B. Covit, K. S. Ryman, A. Shaknovich, K. Pondolfino, M. Clark, M. J. F. Camargo, R. M. Scarborough, and J. A. Lewicki. 1986. Atrial natriuretic factor in normal subjects and heart failure patients. Plasma levels and renal, hormonal, and hemodynamic responses to peptide infusion. $J$. Clin. Invest. 78:1362-1374.

28. Riegger, G. A. J., E. P. Kromer, and K. Kochsiek. 1986. Human atrial natriuretic peptide: Plasma levels, hemodynamic, hormonal and renal effects in patients with severe congestive heart failure. J. Cardiovasc. Pharmacol. 8:1107-1112.

29. Zimmerman, R. S., J. A. Schirger, B. S. Edwards, T. J. Schwab, D. M. Heublein, and J. C. Burnett, Jr. 1987. Cardio-renal-endocrine dynamics during stepwise infusion of physiologic and pharmacologic concentrations of atrial natriuretic factor in the dog. Circ. Res. 60:6369.

30. von Schroeder, H. P., E. Nishimura, C. H. S. McIntosh, A. M. J. Buchan, N. Wilson, and J. R. Ledsome. 1985. Autoradiographic localization of binding sites for atrial natriuretic factor. Can. $J$. Physiol. Pharmacol. 63:1373-1377.

31. Lang, R. E., R. Dietz, A. Merkel, T. Unger, H. Ruskoaho, and D. Ganten. 1986. Plasma atrial natriuretic peptide values in cardiac disease. J. Hypertens. 4(Suppl 2):5119-5123.

32. Hollister, A. S., M. J. Mazer, C. K. Stewart, T. Imada, and T. Inagami. 1987. Reduced atrial natriuretic factor clearance by the stenotic kidney in human renovascular hypertension. Circulation. 76:IV271. (Abstr.)

33. Olins, G. M., K. L. Spear, N. R. Siegel, and H. A. ZurcherNeely. 1987. Inactivation of atrial natriuretic factor by the renal brush border. Biochim. Biophys. Acta. 901:97-100.

34. Koehn, J. A., J. A. Norman, B. N. Jones, L. LeSueur, Y. Sakane, and R. D. Ghai. 1987. Degradation of atrial natriuretic factor by kidney cortex membranes. J. Biol. Chem. 262:11623-11627. 